\title{
ArTesanas Y ARTESANíAs: INDÍGENAS Y MESTIZAS DE CHIAPAS CONSTRUYENDO ESPACIOS DE CAMBIO
}

\author{
Teresa Ramos Maza
}

\author{
"Yo siempre trabajo con mis manos, \\ luchando con mis manos, \\ tejiendo todo lo que sé

(Artesana tseltal)

\section{Introducción}

$\mathrm{E}$ 1 propósito de este artículo es mostrar que las mujeres indígenas artesanas y comerciantes mestizas de los Altos de Chiapas, han creado una nueva artesanía textil que se ha originado a partir de la conjunción de creatividades, intereses y habilidades de las artesanas tseltales y las comerciantes mestizas. Una de sus consecuencias es que se ha creado un espacio a través del cual han obtenido una mayor capacidad de tomar decisiones al interior de la familia, de manejar y controlar recursos, y de participar en la actividad política de sus localidades.

Para situar este estudio en un contexto más amplio describo y discuto las diferentes modalidades o vías que han seguido las familias artesanas de algunas regiones del país para documentar los cambios, adaptaciones y nuevos significados en la producción y consumo de las artesanías en el México del siglo xxi. También reviso y discuto los diferentes hallazgos de estudios realizados sobre el trabajo a domicilio en áreas rurales del país, y sus efectos en las relaciones sociales y de género. Propongo que a través de las diferentes vías de la producción de artesanías en nuestro país, se ha dado también una diferenciación del trabajo a domicilio y de formas de Teresa Ramos Maza, CESMECA-UNICACH. vivir el trabajo femenino y lo doméstico. Estas formas de trabajo no necesariamente significan un confinamiento de la mujer que propicia o refuerza una condición de subordinación femenina.

\section{Artesanías: globalización e interculturalidad}

En la Ciudad de México, a fines del siglo xx, recorriendo un supermercado me llamó la atención un grupo de personas observando muy atentamente un escaparate: ¿qué nueva tecnología doméstica llama tanto la atención de los cslientes? Para mi sorpresa no se trataba de la transmisión televisiva de una visita del Papa, tampoco de un partido de fútbol; el hecho que provocaba la curiosidad de la gente era la exhibición de un anciano artesano que al igual que un malabarista del circo, trabajaba hábilmente con sus pies, manos y boca, haciendo molinillos de madera.

Durante la visita a la casa campesina hecha con pencas de maguey y exhibida en el Museo de Culturas Populares, del Distrito Federal, uno se pregunta por la población que habita estas viviendas en el campo mexicano. Probablemente algunos estén en sus poblados, otros en Estados Unidos, algunos tratando de cruzar la frontera. Si se observan los alrededores del museo se puede 
contemplar a varios de ellos vendiendo artesanías en sus improvisados puestos ambulantes para los cuales basta un pedazo de tela extendido sobre la calle.

En la plaza de Coyoacán, Distrito Federal se observa a infinidad de personas haciendo, vendiendo y comprando artesanías. En la exhibición e intercambios pueden estar reunidos a un tiempo huicholes, "deefeños", estadunidenses, franceses, mixtecos tsotsiles, entre otros. Si paseamos por la calle Real de Guadalupe, la calle de las artesanías de San Cristóbal de las Casas, Chiapas, México, fácilmente podremos observar en alguna tienda a las mujeres indígenas y mestizas intercambiando ideas sobre el diseño de alguna prenda textil.

En el México de hoy, las artesanías, contra todas las predicciones, no han desaparecido. Su persistencia se debe en gran parte a la diversidad de estrategias de vida que los artesanos-campesinos han creado. Las artesanías forman parte de la diversidad de productos para el mercado que han cobrado en algunas áreas rurales, tanta o mayor importancia que los productos agrícolas. En las diversas regiones del país, la población rural recurre a múltiples y novedosos caminos no sólo para sobrevivir en su tierra sino también para crear otras formas de vivir y satisfacer nuevas pautas culturales e, incluso, para posibilitar la salida de su territorio en busca de otros empleos y opciones de vida.

Las familias artesanas han recreado y diversificado la producción artesanal de la misma manera en que los habitantes del campo mexicano ha reproducido y diversificado sus espacios. Los cambios en el campo se han dado de acuerdo con la confluencia de factores tales como la migración, las tradiciones y culturas locales de trabajo, la modernización de los servicios públicos y el comportamiento - generalmente desfavorable para ellos-de los mercados nacional e internacional en donde participan sus productos. Así, en algunas regiones desaparecen ocupaciones tradicionales al tiempo que aparecen nuevas, tal como ha sucedido en el Valle del Mezquital y en la región del Bajío (Arizpe, 1978; Arias, 1994).
Mientras en algunos pueblos las actividades artesanales se han perdido para dar paso a procesos de manufactura y maquila industrial, en otros, la artesanía pasa a ser, a la par de la migración, parte esencial de la organización del trabajo familiar. En muchos poblados una de las ocupaciones de los que se quedan es la actividad artesanal. Actualmente se registra un número aproximado de 10 millones de artesanos en el país ${ }^{1}$. Es un hecho conocido que en el campo mexicano la producción agrícola ya no es la actividad sobre la cual recae la organización del trabajo rural y que la importancia concedida a su realización es desigual entre las áreas rurales del país.

Las anteriores imágenes e ideas sobre las familias artesanas y la artesanía en los inicios del siglo XXI me han motivado a plantear entre otras, las siguientes preguntas: ¿qué nuevas prácticas sociales se han generado entre las mujeres involucradas en esta actividad? ¿En ese acto de producir, vender y comprar un objeto de uso reconocido como muestra de la cultura popular, qué nuevas relaciones e interacciones se configuran? ¿Cómo estudiar la artesanía en el México de hoy?

En los siguientes apartados trataré de aproximarme a la respuesta a estas preguntas.

\section{Las artesanías: diversidad en el consumo y la producción}

Como parte de las llamadas culturas populares tradicionales, las artesanías se han reproducido transformándose en gran parte por el interés de los artesanos en mantener su herencia y renovarla al tiempo que obtienen ingresos, establecen relaciones externas y ganan prestigio. Además, existen factores tales como las motivaciones para consumir artesanías de algunos sectores como medio para afirmar identidades o distinguirse por el gusto refinado y tradicional; y la política estatal y promoción gubernamental que usa lo popular para consolidar la unidad nacional al tiempo que estimula la creación de empleos que disminuyan la emigración, fomente la 
exportación y como estrategia que vincula los productos típicos con el sector del turismo, (García Canclini: 1989; (Novelo,V.: 1993).

García Canclini (ibid) ha señalado cómo al tiempo de la reconversión económica y de las políticas gubernamentales, se produce la reconversión realizada por las propias clases populares que adaptan sus saberes y hábitos tradicionales. También sugiere varios elementos básicos para el estudio de las artesanías en la modernidad: a) las culturas campesinas y tradicionales ya no representan la parte mayoritaria de la cultura popular; b) lo popular no se concentra en los objetos; c) lo popular no es monopolio de los sectores populares; d) lo popular ya no es visto por los grupos populares como muestra de un supuesto arraigo a la tradición; y por último, el hecho de que la interacción comercial ha fortalecido también la organización étnica al tiempo que logra mejorar la economía de las familias artesanas.

La moderna producción artesanal mexicana se distingue por la gran heterogeneidad de sus productos, de sus formas de organización y relaciones sociales en el trabajo y distribución y de su consumo. En el siglo xxI, el gusto por y el consumo de las artesanías han sufrido múltiples transformaciones y su valoración ya no se restringe a los sectores "cultos que gustan del arte" y a los intelectuales que admiran y protegen nuestras raíces y ven en las artesanías manifestaciones de resistencia al capitalismo, (Novelo,1993:46). Las artesanías han sido clasificadas en cuatro categorías según el tipo de consumidor: para el turismo masivo-dirigido; para decorar interiores, para el coleccionista y para la galería de arte, (Turok, M., 1988). En el mercado de artesanías se pueden encontrar objetos que son verdaderas piezas de arte y que pueden convertirse en piezas de exhibición en museos hasta objetos que han sido calificados como "objetos chatarra amenazadores de la calidad tradicional y productos de la mercantilización pervertidora", pasando por los productos que desde siempre han sido considerados representativos de la "cultura popular" como las máscaras, los juguetes de hojalata, huipiles, ollas y figuras de barro, canastos y utensilios de cocina, por ejemplo.

Ahora, los objetos artesanales ya no sólo son bienes que adquiere el turista porque representan al "mundo exótico" y cumplen la función de "constancias y recuerdos" del viaje a otros países, sino han pasado a ser objetos de uso cotidiano entre la gente local. Cualquiera que visite algún supermercado en México, Distrito Federal puede observar áreas destinadas a exhibir algún tipo de artesanía. Esto nos habla de que el consumo de artesanías es realizado por sectores más amplios de la población y en los cuales persiste su uso para resaltar un cierto estatus cultural, pero no sólo por ser un producto elaborado manualmente sino que ahora tienen mayor peso otros significados como el carácter estético o el ser un objeto funcional y bello a la vez ${ }^{3}$ (Ejea, 1998).

Si seguimos la pista de las artesanías se pueden observar las nuevas paradojas que han surgido en la globalización ${ }^{4}$ a través de la producción y el consumo de este objeto considerado como expresión de cultura popular tradicional. Cuando en la capital de nuestro país, muchos mexicanos dicen adquirir artesanías por ser representativas de "nuestras raíces" y los significados giran en tomo a la "identidad nacional" (Ejea, ibid.), los artesanos ven y salen al mundo, tejen figuras creadas por Picasso, Escher, reproducen a Van Gogh.

Otro elemento que caracteriza hoy el consumo de artesanías es el hecho de que al mismo tiempo que existe un consumo diferenciado entre los distintos sectores socioeconómicos y culturales -evidente sobre todo en la calidad, precio del producto y sitio de venta-, el objeto artesanal también puede ser visto como un símbolo de acercamiento entre los distintos grupos sociales y diferentes países. He observado en alguna ocasión a turistas europeas, nacionales y mujeres locales sonreír divertidas viéndose así mismas y a las otras portando todas blusas muy parecidas elaboradas por artesanas de los Altos de Chiapas. Un tipo de uniformidad en el vestir 
como el que representa la ropa de mezclilla. Sin embargo, esta uniformidad en el vestir también es muestra de la globalización como un "reordenamiento de las diferencias y desigualdades sin suprimirlas", (García, 1995:13)

\section{Las vías de la artesanía mexicana}

Los intercambios e interacciones entre la economía nacional de mercado y las economías rurales locales han provocado un reordenamiento profundo de las relaciones sociales y políticas que regulan la vida económica y los procesos productivos de las poblaciones rurales. Destacan en estas transformaciones, por una parte, los cambios provocados por la fuerte estatización de las políticas locales y regionales que ha fomentando que el caciquismo y el apego a los proyectos surgidos del interés político, se conviertan en los métodos básicos de distribución de recursos en el campo. Por otro lado, se ha dado un desarrollo de mercados monetarios: las familias campesinas han monetarizado su economía, es decir han ido cobrando importancia las transacciones monetarias de bienes de consumo y de factores de la producción. En algunos espacios rurales, se han individualizado las estrategias de sobrevivencia o acumulación y se han reestructurado las relaciones familiares, tanto por la degradación de los sistemas de autoridad y cooperación de la economía moral de las comunidades agrarias y principalmente por la redefinición de las relaciones de parentesco y reciprocidad causados por la emigración y semiproletarización generalizadas de la población, (Garcia B., y Garcia B., 1992). Por otro lado, se ha señalado también la dificultad de establecer fronteras entre los espacios urbano y rural y sobre todo del carácter del trabajo femenino.

En el contexto anterior, una de las estrategias de la población en la nueva ruralidad mexicana ha sido la renovación o adopción de la actividad artesanal para el mercado. La reconversión de productos artesanales realizada por los productores y consumidores ha dado como resultado la coexistencia de variados procesos productivos que son diferenciados de acuerdo con las características históricas, culturales y socioeconómicas de la población de las distintas regiones. Algunas artesanías han desaparecido por la competencia de artículos industriales, otras aumentan su producción y se renuevan con el aumento de la demanda y otras más han surgido de la noche a la mañana como respuesta a un creciente mercado turístico y a las nuevas significaciones que el consumo de artesanías adquiere entre los grupos sociales locales.

La diversidad de procesos laborales, tipo de productos y relaciones sociales que se han construido en esta reconversión son consecuencia en gran parte de los esfuerzos, la creatividad y capacidad de innovación de las familias artesanas estimuladas de alguna manera por las políticas gubernamentales dirigidas al fomento de las artesanías. Desde la dimensión económica lo anterior demuestra que los grupos rurales indígenas y mestizos, a través de estas estrategias, hacen evidente por un lado, las limitaciones estructurales de recursos y por otro muestran su gran capacidad para transformar parte de sus recursos culturales - como los objetos artesanales-, en una recreación constante que convierte a la tradición en modernidad.

A lo largo del país podemos encontrar en las diferentes regiones una heterogeneidad de procesos artesanales a través de los cuales se han conformado diferentes relaciones sociales que de alguna manera han traído múltiples efectos en la cultura y la organización social de las poblaciones. Actualmente es posible encontrar una variedad de caminos o vías por las que han transitado los artesanos y las artesanías. Existe una diferenciación entre regiones y pueblos. Por ejemplo, en regiones como las Mixtecas guerrerense, poblana, oaxaqueña, se han dado procesos de desaparición de los textiles de lana, la persistencia de objetos como los canastos de palma y la aparición de nuevas actividades manuales como la 
elaboración de sombreros de palma y plástico. Actividad ésta que se realiza en un sistema productivo más complejo, con nuevas formas en la organización del trabajo como la maquila. La elaboración de algunas artesanías como la de las hamacas de Yucatán se ha convertido ahora en proceso industrial. Las hamacas "que son fabricadas en un sistema de manufactura organizada por capitalistas que controlan los medios de producción", (Littlefield, 1976:199).

En el estado de Oaxaca coexisten dos procesos de producción artesanales que pueden ser los mejores ejemplos de los caminos opuestos de las artesanías mexicanas. Los zapotecos de Teotitlán del Valle que se dedican al tejido de tapetes de lana con diseños que reproducen iconografía zapoteca, pinturas de Miró, Picasso y dibujos de Escher y que han sido considerados junto a los nahuas de Ameyaltepec, Guerrero, los otavaleños de Ecuador y los cunas de Panamá, como representativos de los pueblos que han realizado una reconversión exitosa de su artesanía y que se caracterizan por la autogestión y el reforzamiento interno de la identidad cultural local, (García C., 1983; Stephen, 1990; Good-Eshelman, 1988).

En la Mixteca Alta oaxaqueña, una de las regiones del país con mayor número de migrantes, una parte considerable de la población "que se queda" se dedica a la manufactura de productos de palma y de plástico cuyos orígenes se registran a fines del siglo xIX y que en gran parte contribuyó a la desaparición de las artesanías de lana. El sombrero de la Mixteca se realiza en un proceso productivo con una división del trabajo regional, organizado en un conjunto de procesos de trabajo que se extiende por toda la región con una variedad de características técnicas y sociales. Existen pueblos recolectores de la materia prima que es la palma, pueblos que se dedican al tejido de sombreros, otros que sólo elaboran canastos. Familias de propietarios de talleres en donde se planchan y terminan los sombreros. Es un proceso muy parecido al que se dio en la regiones de los Altos y Bajío del occidente de México, donde a principios del siglo $\mathrm{xx}$, todavía varios poblados se dedicaban a la elaboración, a domicilio, de sombreros con una división del trabajo entre las familias: en una casa se tejían; en otras se planchaban, para ser adornados en una tercera. Mientras en el occidente estos procesos de manufactura han dado el paso a nuevos modelos de industrialización, (Arias, P. 1992), en la Mixteca oaxaqueña la elaboración de sombrero a domicilio persiste, ${ }^{5}$ sobre todo en pueblos como Magdalena Peñasco del distrito de Tlaxiaco, donde todavía a fines del siglo xx, algunos niños tejían sombreros debajo de las bancas escolares para esconderse de las maestras y así terminar las docenas de sombrero que debía entregar la familia el fin de semana a los "empleadores", (Ramos, 1994).

Lo anterior habla no sólo de la diversidad de procesos organizativos, estrategias y cambios de los productos artesanales, sino también conduce a reflexionar sobre las condiciones de trabajo y las nuevas desigualdades que se construyen. Así como las familias tejedoras de Teotitlán del Valle han realizado una reconversión exitosa de su artesanía, gran parte de las familias mixtecas han abandonado sus productos artesanales de lana para convertirse en manufactureras de sombreros. A la par de las modificaciones laborales se han dado también nuevas relaciones y diferenciación social. En ambos pueblos existen familias que han logrado mediante la actualización de viejas formas de organización social como la cooperación en el trabajo entre familias ligadas por el parentesco, acumular cierto capital y crear nuevos mecanismos de control sobre algunos sectores de la población. Este fenómeno se presenta también en varios de los pueblos de artesanos, (Castilleja, 1998; Littlefied, ibid; GoodEsheman, 1988). 


\section{Del objeto artesanal a las relaciones sociales: estudios sobre artesanías en México}

El tema de las artesanías en México ha sido ampliamente tratado desde tres líneas principales de interpretación. La primera es la artesanía vista como un objeto artístico parte del patrimonio cultural y tradicional de los pueblos. Sobre esta tradición interpretativa existe una diversidad de estudios descriptivos sobre los objetos artesanales de las diferentes regiones del país y cuya proliferación y difusión se debe en mucho a las políticas estatales orientadas a la consolidación de la unidad nacional y al fomento del empleo rural y generación de divisas, ${ }^{6}$ (Murillo, 1980; Martínez, 1972; Morris, 1977).

La segunda línea es la que se ubica desde la perspectiva antropológica marxista y que caracteriza a la producción artesanal familiar — la forma más común de producir artesanías en las áreas de escaso desarrollo industrial del país_-, como una actividad que es funcional para la acumulación privada de capital por la intermediación que ejercen los comerciantes mestizos mientras que los indígenas artesanos simplemente reproducen su pobreza. Han sido recurrentes los enfoques que consideran que las artesanas y artesanos indígenas no logran mejorar sus condiciones de vida porque la comercialización siempre es realizada por agentes mestizos que son los más beneficiados. El estigma social de "ser indio" es un factor clave que justifica la exclusión de vías para ascender en la formación económica y lograr riqueza, (Novelo, 1976, 1993; Turok, ibid; Littlefield, 1976; Arizpe L. 1976).

Una tercera orientación se encuentra en los estudios culturales que parten de la línea neogramsciana y de la teoría de la reproducción y que consideran a las artesanías como manifestaciones de la cultura de las clases populares que son resultado de la apropiación desigual del capital cultural, la elaboración propia de sus condiciones de vida y su interacción conflictiva con los sectores hegemónicos. Su enfoque considera no sólo las limitaciones socioeconómicas estructurales sino también las respuestas y formas de adaptación y resistencia de los pueblos mestizos y las comunidades tradicionales a la dominación. Al tiempo de la reconversión económica macroestructural se produce la reconversión realizada por las propias clases populares que adaptan sus saberes y hábitos tradicionales, (García C., 1984, 1989). Dentro de la última corriente, algunos estudios antropológicos - como dije anteriormente- constatan cómo algunos pueblos de artesanos de México y América Latina han creado sus formas de modernizarse reelaborando sus tradiciones a través de la participación en el mercado. Esto ha significado no sólo una mejoría en sus ingresos sino también una reafirmación simbólica, (García C., 1989; Good-Eshelman ibid; Stephen,1990).

Sobre lo anterior me interesa destacar dos cuestiones: por una parte considero que, si bien es cierto que algunos elementos de identidad se reforzaron y que, en este sentido se puede esperar una mayor cohesión social, también se han creado nuevas desigualdades que conducen a desintegraciones y ponen en tensión las formas de cooperación locales, (Stephen, 1990; Littlefield, ibid; Clements, 1988). Por otro lado, es evidente que el enfoque que analiza las relaciones sociales conformadas en la producción de artesanías desde la visión que las considera como relaciones de explotación entre mestizos e indígenas, resultó insuficiente para explicar la diversidad de nuevas relaciones y formas de resistencia que los pueblos indígenas han instrumentado en la búsqueda de alternativas de vida.

Los procesos anteriormente descritos resultan entonces en nuevas situaciones de desigualdad no sólo entre las familias sino también entre los géneros. Si la comercialización de artesanías favorece a ciertos sectores de artesanos como grupos étnicos, provoca también efectos negativos en la situación de las mujeres. Los hallazgos de Stephen (1991) demuestran que se da una desigualdad económica y social entre las familias, pasando unas a ser trabajadoras mientras otras se enriquecen y 
forman parte de una naciente clase patronal y que las mujeres pertenecientes a estas últimas familias fueron las menos beneficiadas en las relaciones de género, comprobando con ello que las desigualdades sociales no se presentan de forma aditiva, sino que la mujer puede tener una mejor posición socioeconómica y estar en desventaja en las relaciones de género y viceversa.

\section{De la artesanía a las artesanas}

La conjunción de la antropología de género y los estudios culturales sobre artesanía ha resultado en valiosos trabajos que analizan la diferente inserción de las mujeres en actividades remuneradas y sus consecuencias en la familia y en la condición social femenina. Así, en el caso de las familias zapotecas de Teotitlán del Valle, Oaxaca, se encontró que las relaciones de género que existían en el trabajo agrícola y en los hogares de tejedores cambiaron radicalmente a medida que las familias comerciantes acumularon capital y contrataron trabajadores. Las esposas de los comerciantes de tejidos fueron marginadas por su falta de experiencia y educación. En cambio, las mujeres maquiladoras y tejedoras independientes desarrollaron el proceso de producción en un esfuerzo conjunto con sus esposos e hijos; ellas tuvieron un alto nivel de control sobre las decisiones y el ingreso es manejado por la mujer y el hombre. En este grupo de familias trabajadoras los resultados de la comercialización de tejidos fueron contradictorios: por una parte, ellas mantuvieron el control del proceso de producción; y por otra, sus familias no se beneficiaron de la misma manera que las familias de los comerciantes. Estos resultados demuestran cómo las desigualdades sociales no se presentan de forma aditiva, sino que la mujer puede tener una mejor posición socioeconómica y estar en desventaja en las relaciones de género y viceversa, (Stephen, ibid).

Varios de los trabajos sobre las mujeres artesanas se insertan en el conjunto de estudios sobre el impacto de las transformaciones de la agricultura en la situación de las mujeres rurales y han estado orientados principalmente por dos líneas teóricas. La primera se ubica en la corriente estructuralista-marxista y su vertiente marxista-socialista que predominaron durante las décadas de los setenta y ochenta. Desde una visión determinista, esta corriente otorga un papel predominante a los factores macroeconómicos como impulsores de los cambios en las condiciones de vida de las mujeres y concibe al patriarcado ${ }^{7}$ como una dimensión de la estructura social y causa de la opresión de la mujer.

Desde la perspectiva anterior, la persistencia de las artesanías ha sido vista como una actividad productiva que reproduce una forma doméstica de producción basada en tradiciones patriarcales en donde el trabajo de la mujer es culturalmente devaluado y los hombres son los que controlan las utilidades. A partir de estos planteamientos se ha concluido, por ejemplo, que el trabajo de las alfareras de Amatenango del Valle, Chiapas, es explotado por el hombre gracias a la existencia de una estructura patriarcal con formas de control sobre el trabajo de la mujer que son actualmente reproducidas a través de la alfarería. Debido a esta situación tampoco existe un interés entre las alfareras de introducir cambios tecnológicos, (Nash, 1994).

Las conclusiones anteriores se derivan de lo que la corriente feminista de la igualdad ha tomado como cualidades inherentes a las identidades de género creadas por una división del trabajo que siempre separa las actividades masculinas y productivas y las femeninas y reproductivas, sin atender entre otros, al hecho de que la cultura laboral campesina e indígena es distinta de las culturales laborales urbanas y de regiones altamente industrializadas, (Ramos, 2000). Son parte de lo que Pancake (1993) critica y denomina generizaciones infundadas y que consisten en suponer fronteras rígidas de género en la división del trabajo artesanal, en este caso de textiles; son los hombres los que tejen para el mercado, los que introducen innovaciones técnicas y los que se ocupan de 
las transacciones con el exterior, mientras las mujeres producen para el autoconsumo, sin aceptar nuevas tecnologías y manteniéndose alejadas de los circuitos comerciales. Este tipo de conclusiones sobre producción y comercialización artesanal de población de origen maya, difiere de los hallazgos sobre los tejidos de Guatemala. Por el contrario, lo que esta autora demuestra a través de su información etnográfica, es que tanto hombres como mujeres manejan indistintamente materiales e instrumentos de trabajo iguales; que la mayoría de las mujeres tejen también para el mercado y tanto el hombre como la mujer administran sus ingresos por separado. Por último, concluye que las tejedoras también están conscientes y son sensibles de la demanda del mercado (1993:270-274).

La segunda línea teórica se orienta al estudio de las prácticas y factores culturales y políticos locales. Parte de hacer una crítica a los enfoques que consideran los espacios y roles de género de la mujer como restringidos y estáticos y los del hombre como amplios y públicos. La categoría género y las identidades de género son tratados como elementos dinámicos y desde una perspectiva situacional y posicional que se definen en la interacción cotidiana, (Mummert y Ramírez, 1998; Alberti, 1994; Mora, 1998; Moctezuma, 1998; Rosado, 1998; Aguiar, 1998; Lazos, 1995).

En este nuevo enfoque, el trabajo de las mujeres es visto ahora como una relación social y no sólo como una actividad productiva y contribuyen a explicar la relación entre el trabajo y la redefinición de la identidad de las mujeres, aspecto muy importante para conocer no sólo los cambios actuales sino cómo se ha valorado su trabajo y cómo lo perciben las mujeres mismas. Se consideran también las iniciativas que ellas han tenido en el diseño de alternativas de resistencia ante factores estructurales que las marginan. Otro de los aspectos muy importantes considerados es el estudio de las maneras en que las mujeres ejercen poder o autoridad. Entre las artesanas de Cuetzalan, Puebla,__producen textiles y productos de fibras naturales como cestos y huacalesAlberti (1995) encuentra una nueva posición genérica a partir de su experiencia organizativa para capacitación y comercialización de sus productos. Las alfareras de Patamban y artesanas de Jarácuaro, Michoacán tienen un papel muy importante por su conocimiento y participación en los sistemas de cargo y a través de éste logran consolidar también su actividad productiva, (Moctezuma, ibid.; Castilleja, ibid.)

Los estudios de caso realizados en contextos locales y particulares confirman que la división del trabajo no siempre resulta en una condición de dominio de los hombres hacia las mujeres y en una subvaloración de su trabajo. Son muestra también de que no sólo no han perdido parte de las actividades domiciliarias generadoras de ingresos como las artesanías sino de cómo, en el contexto del desarrollo de capital y las transformaciones agrarias en México, las mujeres han tenido sus propias respuestas a través de las cuales han reconfigurado la identidad femenina. De ahí la importancia de considerar los hallazgos que nos presentan los estudios de caso más recientes, los cuales confirman la existencia de espacios de acción que las mujeres han ocupado por decisión propia y que nos dicen que probablemente la identidad femenina está moldeada, construida por algo más que las experiencias de procesos sociales de exclusión, supuestamente relacionada con su sexo y cuyo papel en la sociedad es la reproducción biológica y la reproducción de la fuerza de trabajo.

\section{Las vías de las artesanas de los Altos}

En nuestra globalización es posible distinguir principalmente dos vías recorridas por las artesanas textileras de esta región: una consiste en el paso de la producción y venta de textiles en forma individual o a través de la intermediación y colaboración en redes familiares, a la vinculación con organizaciones formales; la segunda la ubico en la modalidad de producción y 
comercialización entre grupos informales de artesanas indígenas y comerciantes mestizas de San Cristóbal y de otros lugares del país y extranjeras.

Distingo estas vías con base en las formas en que las artesanas han elegido para obtener apoyos para la producción y comercialización y que implican distintas relaciones con otros grupos sociales, consecuencias en su condición e identidad social y diferentes efectos en la producción. Es suficientemente conocido el hecho de que a partir de los años ochenta se dio la proliferación de organizaciones de productores campesinos indígenas entre las cuales las de artesanas han tenido un lugar destacado. Éstas han sido promovidas por diferentes agentes sociales, desde el Estado, a través de la política indigenista operada en gran parte por el Centro Coordinador Tseltal-Tsotsil del Instituto Nacional Indigenista e instituciones oficiales y programas de desarrollo, asociaciones y cooperativas sociales como el DIF, SEDESOL, PRODECH, entre otros. La promoción y auge de las organizaciones de artesanas fue tan amplio que actualmente es común encontrar artesanas en todos los pueblos de la región, que han formado parte de por lo menos una cooperativa, Sociedad de Solidaridad Social, Unidad Agrícola de Producción de la Mujer o alguna otra asociación promovida por organismos no gubernamentales.

En los textiles se ha originado una diversificación en la producción: variación en los diseños de brocados, bordados, tipo de prendas y materiales y básicamente se pueden distinguir dos clases de textiles: La primera es el conjunto de textiles que son elaborados por las artesanas que continúan trabajando con sus técnicas y materiales originales — lana, hilos de algodón y tintes naturales_- Ellas organizan su trabajo de tejido generalmente en sus viviendas en combinación con actividades domésticas y en ocasiones trabajan en los talleres instalados por las cooperativas y asociaciones en donde también se proporciona capacitación en aspectos técnicos como el teñido de fibras y diseños.
En esta modalidad se pueden ubicar a las artesanas tsotsiles de Larráinzar, Chenalhó, Chamula, Zinancantan, Pantelhó y el pueblo tseltal de Tenejapa, principalmente. Es la vía de la tradición y el arte textil. Estos textiles son hechos en telares de cintura con las técnicas originales de las indígenas y son considerados representativos de la cultura maya de esta área del sureste. Son las piezas confeccionadas con un fuerte contenido de simbolismo ancestral, en el que se repiten las referencias simbólicas de la cosmovisión maya y cristiana, "los caminos del cielo, el lugar de las estrellas, los secretos de la agricultura, los lugares míticos que albergan a los dioses, las cuevas (...) que han sido transmitidos de generación en generación hasta la actualidad", (Fábregas, 1993:27; Turok, 1988). La calidad de los textiles es variable. Hay piezas que son verdaderas obras de arte y que por su altos precios sólo pueden ser adquiridos por sectores nacionales y extranjeros de clases media y alta o ser canalizados al mercado internacional.

En la promoción, capacitación y financiamiento de este tipo de artesanías han participado todos los organismos gubernamentales y no gubernamentales, pero la que ha tenido más éxito y mayor control en la calidad de sus productos es la asociación Sna' Jolobil (Casa del tejido) que se ha especializado en la exportación de esta clase de textiles. Muchas de las artesanas que han seguido esta vía trabajan o han trabajado con ella. Es la más antigua organización de artesanas de los Altos y fue creada en 1976 como sociedad cooperativa con apoyo del Fondo Nacional para el Fomento de las Artesanías, (Hernández y Narváez, 1992). Sus objetivos principales giran en torno al "rescate y revitalización de las técnicas tradicionales del tejido, brocado, bordados e hilados", (ibid:109). Dos de sus fundadores W. Morris y Petul - tejedor indígena - se relacionaron con grupos de artesanas — principalmente de San Andrés Larráinzar y'Tenejapa - a través de Fonart y fue el primero quien decidió que la organización no vendería artesanías sino arte textil, (Vargas, G. s/f). Otra de sus características es 
la composición de su membresía honorífica de la que forman parte varios extranjeros que hacen una labor de difusión, promoción cultural y aportan donaciones. Se ha señalado que esta organización, más que ser una cooperativa real funciona como una empresa comercial cuyos socios principales, el uno estadunidense y el otro indígena de los Altos, se han encargado de la difusión internacional de las técnicas, diseños, las formas de vida de las artesanas y la relación del brocado con sus sueños, (Vargas, ibid). Alrededor de esta tienda existen grupos de artesanas que entregan textiles a consignación y otras que son contratadas como trabajadoras por encargo previa selección y comprobación de la calidad de sus tejidos y bordados.

Otro tipo de organización es el que se relaciona con el conjunto de cooperativas y sociedades que han sido promovidas por los programas gubernamentales de apoyo financiero y promoción de las artesanías. La primera de este tipo es la J'pas Joloviletik (Las que hacen tejido) que fue fundada en 1984 y que llegó a reunir un número de 800 artesanas de 23 comunidades y nueve municipios de la región. El modelo de funcionamiento de esta cooperativa impulsada por el Instituto Nacional Indigenista fue retomado por innumerables grupos de artesanas de todos los municipios de los Altos para formar sus cooperativas que en muchos de los casos han tenido la figura jurídica de Sociedad de Solidaridad Social y que se han caracterizado por la formación y consolidación de lideres que han hecho el papel de intermediarias entre funcionarios de gobierno y los grupos locales. En este sentido, con muchos de estos grupos ha sucedido lo mismo que muchas organizaciones de productores hombres. "Conviene recordar — dice Castro, (s/f) - " "que el trabajo que el INI hizo a lo largo de los años fue ..formar nuevos y nuevas caciques al empoderar a unas cuantas personas sin buscar que éstas reprodujeran lo aprendido en sus comunidades de origen", (ibid:2). Estas asociaciones generalmente se han vinculado, además del INI, con dependencias oficiales como el Instituto de las Artesanías, el antiguo DIF, la Secretaría de los Pueblos Indios, entre otras.

El papel de las primeras asociaciones de indígenas que se relacionaron con organismos y fundaciones internacionales como la Sna'Jolobil y las asociaciones ligadas a las instituciones gubernamentales ha sido ampliamente rebasado por la proliferación de organizaciones no gubernamentales conformadas por artesanas indígenas y asesoras nacionales y extranjeras. Estas organizaciones no gubernamentales han incluido como principio fundamental de sus acciones la perspectiva de género, perspectiva orientada a "vincular los programas de desarrollo a la solución de necesidades inmediatas de las mujeres indígenas cuidando de preservar su cultura e identidad étnicas", (Olivera, 1994:67).

Esta perspectiva de género por un lado se identifica con la práctica y política feminista no sólo de las asesoras universitarias de las ONG's, sino de las necesidades prácticas sentidas por muchas de las mujeres indígenas. Por otro lado, también se relaciona con la corriente globalizadora del enfoque de género impulsada por organismos internacionales como algunas instancias de las Naciones Unidas y retomada por muchos de los organismos e instituciones gubernamentales vinculadas al desarrollo comunitario y que se convirtió en algunos ámbitos casi un requisito para obtener financiamiento para proyectos. Es interesante anotar al margen que, esta corriente ha promovido y abierto espacios en las organizaciones de productores hombres a programas específicos de mujeres.

Lo anterior es parte de los procesos de globalización que son resultado de prácticas sociales específicas articuladoras de lo local-global y que se producen y reproducen como parte de lo que Mato (2001), denomina "complejos transnacionales de producción cultural" y en donde circulan representaciones ${ }^{8}$ de ideas como etnicidad, identidades, género, medio ambiente o desarrollo sostenible, entre otras. 
La circulación de artesanías en la región actualmente tiene un nuevo significado que trasciende la función de sowveniry de contenido estético para adquirir un contenido político. Hoy también algunas indígenas también han salido a recorrer el mundo portando sus textiles; la artesanía chiapaneca es comprada en Europa y Estados Unidos también por solidaridad con el movimiento zapatista e indígena. Si bien los textiles chiapanecos compiten desventajosamente en el mercado internacional con los textiles asiáticos, hindués y de otros países de América Latina, ahora son apreciados y adquiridos porque simbolizan un movimiento indígena y en particular un movimiento de lucha por los derechos de las artesanas indígenas. Se ha señalado que la politización de la indianidad y la transformación de las cooperativas y asociaciones de artesanías en actores importantes en el desarrollo económico de sus pueblos son dos elementos que contribuyen a un clima favorable para la comercialización de los textiles chiapanecos, (Vargas, s/f: 174).

Un notable ejemplo de lo anterior puede ser la organización independiente Jolom Mayaetik (Tejedoras Mayas) que surge en 1995 por la división dela cooperativa del INI entre mujeres ligadas al PRI y mujeres simpatizantes del PRD y del EZLN. Este tipo de organización puede ser un buen ejemplo de la rápida transición de las artesanas indígenas del textil a la política y al mundo. Sin embargo, la historia de la J'pas Joloviletik nos ilustra sobre cómo un grupo de ellas se enfrentó al poder de una lideresa artesana priista ${ }^{9}$ que quería imponer a su hijo como asesor de la cooperativa, mientras muchas de las mujeres querían a la asesora propuesta por el director del Centro Indigenista. Las mujeres de San Andrés Larráinzar principalmente cuestionaron el hecho argumentando que "él es hombre y son las mujeres las que tienen que decidir" además de criticar los vínculos de esta persona con el en ese entonces gobernador priista, (Castro, ibid.). De esta manera, la cooperativa tuvo como asesora a una mestiza universitaria y posteriormente a un equipo de asesoras indígenas y mestizas que le ha dado un fuerte impulso a través de la construcción de redes de apoyo internacional y capacitación para la autogestión. Las artesanas de la Jolom han participado en las mesas de discusión con representantes de gobierno y el ejército zapatista, han ampliado también las redes de apoyo para comercialización y organizado exposiciones en ferias nacionales e internacionales.

Las distintas experiencias organizativas y de producción de las textileras de Los Altos de Chiapas descritas demuestran que un sector muy importante de artesanas han optado por integrarse a cooperativas y organizaciones como una práctica que les facilita el acceso a la comercialización y a la gestión de recursos para producir sus textiles. También muestran la necesidad de recurrir cada vez más a los contactos con fundaciones extranjeras para contar con financiamientos. Considero que el aspecto más relevante de esta vía organizativa de las artesanas son los cambios muy importantes en el conjunto de valores, actitudes y conocimientos de las mujeres, sobre todo de las pertenecientes a las generaciones más jóvenes. Hay ahora jóvenes indígenas que "dudan en casarse porque piensan que son más independientes siendo solteras", (Vargas, s/f.:170). La vía del comercio mediante la pertenencia a una organización ha sido también un camino para canalizar su participación política de manera más amplia. Esta participación puede dividirse entre mujeres que son priistas y/o oficiales y que están identificadas con las organizaciones más relacionadas con instituciones gubernamentales; y la otra línea formada por artesanas simpatizantes de otros partidos como el PRD y del movimiento zapatista.

A fines del siglo $\mathrm{xx}$, los textiles chiapanecos pasan entonces a formar parte de nuevos consumos parte de los ideoscapes, es decir, los flujos de ideas, términos e imágenes que incluyen bienestar, soberanía, representación y democracia (Appadurai, 1996), y que se concretizan en los movimientos sociales mundiales por derechos 
humanos, medio ambiente, solidaridad con los pueblos indios, etcétera. Considero que las artesanas y sus asesoras, asesores y líderes en sus crecientes y múltiples contactos con el exterior han impulsado una globalización desde abajo como respuesta a otros procesos de globalización, (Mato, 2002).

\section{Indígenas y mestizas construyendo espacios de cambio}

Ahora quiero referirme a la que considero como la segunda vía del textil de los Altos y que se relaciona con el nuevo textil originado a partir de la conjunción de creatividades, intereses y habilidades de varios grupos sociales: indígenas y mestizas y más recientemente extranjeras. Dos grupos sociales que han sido vistos históricamente como antagónicos: mestizas coletas y mujeres indígenas han creado un espacio donde todas han participado aportando nuevas ideas y con ello recreando textiles que ahora son distribuidos en varias partes del mundo. Estas prendas han sido diseñadas a partir de la vestimenta original del pueblo tsetal de Aguacatenango. ${ }^{10}$ Son prendas que se caracterizan por tener diseños sencillos y estar elaboradas con materiales industriales como la manta e hilos de algodón. La técnica manual y sus bordados menos sofisticados se han prestado más fácilmente a una mayor diversificación e innovaciones.

De este último modelo de textiles me interesa destacar los siguientes aspectos: 1) que esta vía ha hecho posible para mujeres rurales y urbanas un nuevo espacio de mayor independencia y control de recursos, autogestión y participación al tiempo que han creado juntas también un nueva artesanía textil que se ha originado a partir de la conjunción de sus creatividades, intereses y habilidades en constante tensión entre el conflicto y la cooperación; 2) que las relaciones sociales creadas a través del trabajo no han sido siempre desventajosas para las artesanas indígenas en contraparte de las ventajas de las comerciantes mestizas y; 3) que el modelo de trabajo a domicilio creado en esta área textilera no ha resultado en una confinamiento de la mujer al interior de sus viviendas, posibilitando con ello una probable subordinación y dependencia del hombre. Tanto la producción como la comercialización son actividades que las mujeres tienen que realizar saliendo de sus hogares y sus localidades.

En Los Altos de Chiapas, las mujeres reconfiguran el trabajo a domicilio; mujeres indígenas y mestizas en su encuentro en la producción textilera abrieron las puertas a una expansión exitosa de una manufactura en pequeña escala que articula redes de artesanas, comerciantes y trabajadoras habitantes de pueblos y ciudades de la microrregión que ha expandido en corto tiempo el mercado de trabajo femenino. Esta producción se extiende en un área que comprende los valles de San Cristóbal, valle Teopisca-Amatenango del Valle y parte del valle de Villa las Rosas. ${ }^{11}$

La manufactura de blusas en esta microrregión ha sido organizada en sus orígenes por mujeres tseltales y mestizas coletas ${ }^{12}$ de la ciudad de San Cristóbal. En este sentido, este espacio productivo puede verse no sólo como una vía que ha contribuido a generar empleos remunerados para un sector de la población femenina, sino también como un espacio que las mismas mujeres han construido y que en su versión moderna se opone a la realidad de la época de la colonia, cuando las indígenas realizaban un trabajo forzado obligadas por el encomendero español a tejer. Los orígenes de este novedoso proceso de artesanía textil pueden ser localizados desde las antiguas relaciones de intercambio intrarregional entre indígenas y mestizos. Las comerciantes de artesanías de San Cristóbal pertenecen a familias de que se establecieron en una de las principales calles de la ciudad y cuya especialización comercial fue el intercambio de productos industriales con productos artesanales y agrícolas producidos por las familias indígenas. 
El trabajo de las indígenas en la manufactura de textiles fue objeto de mecanismos de coerción social de los españoles, como el pago de tributo, pues "en la segunda mitad del siglo XVI era común entre los encomenderos sacar indias de sus pueblos y situarlas en lugares cerrados, como corrales, donde las obligaban a tejer vestidos de algodón y lana en pago de tributo. En 1549 el rey prohibió "que se encierren en corrales a las indias a hilar" y que se les permita estar en sus casas para realizar dicho trabajo", (Bonnarcorsi,1990). Maurer (s/f) documenta también sobre el repartimiento de hilaza entre las mujeres de los poblados. Los Corregidores distribuían cuatro veces al año pacas de algodón para que las mujeres las hilaran ya sea en forma gratuita o pagándoles precios ínfimos. Esta información histórica nos presenta antecedentes sobre el trabajo de textiles en la región y nos da una idea de las relaciones de explotación entre españoles y mujeres indígenas. Hoy, que son las mujeres las que se han apropiado de esta actividad, qué relaciones establecen y cómo y quiénes han salido beneficiadas? $¿$ Es posible suponer a las comerciantes mestizas como las nuevas explotadoras de las indígenas?

Bourdieu (1995) señala que no es posible conformarse con un modelo explicativo que sea incapaz de diferenciar las posiciones que la intuición ordinaria del universo en cuestión opone fuertemente entre sí. Considero que para el estudio de las relaciones entre estos grupos de mujeres no me puedo quedar con el modelo que propone considerar estas relaciones como simples relaciones de integración económica, explotación y odio en el ejercicio del "poder interétnico". Esta realidad que se nos presenta es más compleja que el suponer que si todas comparten una misma subordinación como mujeres podrían establecer alianzas en contra del dominio masculino o de suponer que las mestizas por ser de un grupo étnico visto históricamente como dominante y explotador de los indígenas, sean las representantes en el siglo XxI de los corregidores del siglo XVIII. Considero también que en este encuentro de identidades femeninas diferentes se pueden dar diversas formas de cooperación y de conflicto en cuanto que se utilizan mecanismos de coerción social según los capitales movilizados entre cada grupo y al interior de éstos, al tiempo que se intercambian conocimientos y experiencias cotidianas.

\section{El moderno trabajo a domicilio: artesanas tseltales de los Altos de Chiapas}

Esta producción textilera es un proceso que se ha dado a lo largo de 40 años y tuvo en sus orígenes una división del trabajo entre las mestizas y las tseltales. Las primeras se dedicaron al comercio y las segundas a elaborar y vender sus artesanías. Posteriormente las comerciantes se especializaron en el corte y diseño de prendas y en emplear a las artesanas quienes realizan el bordado según sus habilidades y creatividad. En los años ochenta empezaron a involucrarse en esta actividad mujeres de otras partes del país y que establecieron tiendas de ropa artesanal en diferentes puntos de la ciudad. En esos tiempos era común ver a mujeres tseltales bordando sus racimos de flores sentadas en las orillas de las banquetas vecinas del establecimiento comercial que las contrataba para el bordado de vestidos, faldas, entre otras prendas. Las mujeres de estos establecimientos constantemente se quejaban de cómo sus diseños eran "copiados" por las "mujeres de Real de Guadalupe". Las blusas elaboradas por las artesanas que trabajaban con las comerciantes coletas tenías diseños más apegados a la vestimenta propia de las tseltales, en cambio las prendas que se confeccionaban entre comerciantes "fuereñas" $y$ bordadoras indígenas incluían nuevos y diversos diseños. De esta manera las flores de cuatro pétalos de la fachada de la iglesia de San Agustín (siglo XVII) que pertenecía al Colegio Jesuita ${ }^{13}$ de San Cristóbal se repiten en un diseño del textil de Aguacatenango.

En esa época se conformaron dos modalidades en el trabajo del bordado de textiles: la contratación de bordadoras que se trasladaban de sus pueblos a San 
Cristóbal para bordar en los locales y en las calles; y la modalidad de encargo de las comerciantes de Real de Guadalupe, quienes proporcionaban los materiales para que las tseltales los trabajaran en sus hogares. Se da entonces un crecimiento continuo del trabajo a domicilio bajo la modalidad de "maquila", iniciado años atrás como resultado de los intercambios en especie entre los indígenas y los comerciantes de la Calle Real de San Cristóbal. Respecto al sistema de comercialización de las artesanías, éste se ha realizado bajo tres modalidades: 1) la artesana vende su textil directamente al consumidor; 2) las indígenas venden las prendas a las comerciantes mestizas; 3) las indígenas reciben de las comerciantes, tanto la materia prima como los diseños para trabajarlas en sus poblados. Las comerciantes coletas pasan así a controlar parte del proceso productivo y las artesanas se convierten en trabajadoras a domicilio (Rus, 1990). Sobre este punto es importante aclarar que la última modalidad se origina en la producción de textiles que se elaboran con insumos industriales como la tela de manta e hilazas de algodón.

En la actualidad, la vestimenta que las tseltales han usado desde hace mucho tiempo ha sido transformada para el mercado a través de la creatividad, habilidad y diversos conocimientos de las mujeres tsetales y mestizas. Las relaciones e interacciones de las mujeres en esta artesanías ha resultado en cambios que ellas aprecian como favorables. Ha permitido también que algunas de ellas no sólo regresen a su situación de artesanas independientes sino que se conviertan en empleadoras, pues como dice doña Mariana: las mijeres se avivaron, nos avivamos, cuando las mijeres de San Cristóbal nos dan la ropa, la podemos desbaratar y de alli sacamos el modelo y asi, vamos haciendo y abora nosotros hacemos todo, nosotros dimos la tira, la tira que lleva flores bordadas porque esa es la blusa antigua de nosotros, el blusón que usamos desde nuestras abuelas... y asi fue saliendo estas blusas... y las mujeres de las artesanias de San Cristóbal fueron poniendo también sus pensamientos... (artesanas tseltales).
Han sido documentadas también las condiciones de trabajo y modificaciones sufridas en la situación de las mujeres trabajadoras. Varios trabajos realizados en diversos lugares en varias regiones de México y del mundo dan cuenta de estos aspectos. La ocupación de las mujeres en el trabajo a domicilio ha sido vista como el resultado de las grandes transformaciones en la división internacional del trabajo, misma que observa para los países subdesarrollados, un proceso creciente de incorporación de la mujer al trabajo asalariado y actividades remuneradas, básicamente, en plantas maquiladoras, agroindustrias, comercio ambulante, empleo doméstico y demás actividades que se ubican en el sector de la economía llamado "informal". Con la utilización de esta mano de obra femenina, se reducen costos a través de formas de producción descentralizadas, fragmentadas y de gran flexibilidad que son funcionales para un mercado de fluctuaciones constantes y en donde el productor tiene un grado relativamente elevado de control sobre el proceso laboral, ningún control sobre el producto y ningún contacto con el mercado y el uso de salario a destajo como forma de pago, (Nash, 1994; Salles y González, 1994; Benería L. y Roldán, 1992). El estudio sobre trabajadoras de barrios y colonias de la Ciudad de México y del área metropolitana, revela que este tipo de trabajo industrial doméstico es una forma de producción explotadora disfrazada de subproletarización y en donde no se encontró que "el control de la mujer sobre sus ingresos le otorgara facultades de importancia para el regateo de las relaciones de género dentro del hogar", (Benería y Roldán, ibid:196). Por otra parte, se ha señalado también la dificultad de establecer fronteras entre los espacios urbano y rural y sobre todo del carácter del trabajo femenino. Después de la crisis de 1982, las mujeres rurales han tenido como destino en primer lugar, las áreas urbanas de 20000 habitantes y más, segundo, las grandes ciudades, y tercer lugar de destino alguna otra zona rural, (Lara, 1995). 
Este tipo de trabajo a domicilio, ha sido caracterizado por Nash (1992) como la actividad clandestina en donde las mujeres son explotadas más fuertemente que nunca. Se ha dicho también que este tipo de trabajos vinculado a circuitos comerciales, aun en ámbitos marginados, también logran abrir espacios en donde las mujeres pueden interactuar, aprender y aprovechar caminos para una mayor independencia y valoración personal. (Oliveira,1989). Las mujeres han desarrollado estrategias de acomodo para desempeñar nuevas actividades sin descuidar una de las actividades de su ámbito como es la responsabilidad de los trabajos de reproducción. Quizás para la comerciante coleta ${ }^{14}$ puede ser que el comercio de artesanías signifique una manera de hacer dinero sin salir de su entorno hogareño. También puede ser la forma en que ellas se legitiman ante sus esposos y amistades y le dan sentido a su vida como mujeres. De la misma manera, para las mujeres indígenas la producción de textiles a domicilio, probablemente sea una forma práctica de obtener dinero por su trabajo sin salir todo el tiempo de su pueblo como trabajadora doméstica por ejemplo, y de evitar la compra de insumos. El trabajo a domicilio se presenta así, como una opción que el conjunto de mujeres transforma en otra versión del trabajo femenino rural.

En la literatura de género, un estudio clásico sobre el tema es el de María Mies, (1982) sobre las encajeras de Narsapur, India, en el cual analiza las repercusiones del trabajo a domicilio en la desorganización de las mujeres como trabajadoras. La ideología del ama de casa — según Mies — apoya este sistema de producción en el cual ellas no llegan a conocer el proceso total ni el producto terminado. Dividir el proceso de producción es una estrategia que permite que las mujeres nunca intenten comercializar los encajes por cuenta propia, dando como resultado que el proceso de comercialización esté en manos exclusivamente masculinas. Esta modalidad de trabajo a domicilio puede ser — a distinta escala — incluido también en lo que Appadurai (1996) denomina como fetichismo de la producción transnacional fragmentada, en la cual las relaciones de producción se oscurecen y la localidad se convierte en un "fetiche" que disfraza las fuerzas globales dispersas que controlan realmente el proceso de producción. Esto puede ocurrir en la Mixteca oaxaqueña en la producción de sombreros en donde existe una microespecialización por pueblos y regiones, pero no es el caso de las bordadoras de los Altos.

Entre el trabajo a domicilio de las "encajeras de Narsapur" y el trabajo de las bordadoras de los Altos es posible encontrar algunas similitudes, por ejemplo en las características del bordado de blusas que es realizado en combinación con actividades reproductivas como el cuidado de los hijos. Tanto la fabricación de encaje como la elaboración de blusas representan una oportunidad de combinar las labores domésticas con el trabajo remunerado. Mies llega a la conclusión de que se da una combinación de factores tales como, la ideología cristiana de la mujer como "ama de casa" y la ideología de la casta sobre la reclusión femenina que han resultado en una conjunto particular de relaciones productivas, que garantizan el suministro de mano de obra barata para el sector encajero exportador.

Sin embargo, mientras el trabajo de las encajeras está organizado en un sistema de subcontratación y atomización de la producción que no permite que las mujeres conozcan el proceso global ni se puedan unir para enfrentar a los exportadores, el tipo de textil artesanal local y la modalidad de trabajo a domicilio diseñada por las tseltales y coletas hace posible no sólo que ellas realicen todo el proceso productivo sino que también se conviertan en empleadoras y comerciantes resultando con ello una gran movilidad espacial de las mujeres. Ellas recorren pueblos y ciudades para contratar a otras bordadoras, para vender sus blusas, para ir a "dejar sus trapos que le encargó doña Rosa".

Ahora, el trabajo a domicilio en este caso, no es resultado del proceso de cambio de un sistema artesanal 
independiente a un sistema regional de maquila con una división del trabajo definida entre comunidades y al interior de las familias, sino que se trata de un sistema más complejo que conjunta características de maquila, de artesanía y en donde las mujeres adquieren identidades ${ }^{15}$ laborales múltiples y flexibles. Así una misma mujer puede ser trabajadora y empleadora al mismo tiempo, artesana en algunas épocas y comerciante en otras. Un sistema propio, diría yo, de la moderna artesanía de la que he hablado anteriormente.

Para comparar esta situación con un caso más cercano y destacar las heterogeneidades multitemporales y paradojas de las actividades económicas regionales y los cambios en la situación e identidades femeninas quiero regresar a la región del Bajío Occidental, en donde la doble condición de amas de casa y trabajadoras a domicilio de las mujeres fue la "condición femenina (que) forma parte sin duda del trasfondo que hizo posible, que volvió tan específica como exitosa, que hizo persistir y prosperar hasta nuestros días, a la manufactura francorrinconense, la que ayudó a difundir y expandir como nunca antes el trabajo a domicilio como forma femenina de conseguir dinero", (Arias, ibid:: 241).

El proceso de manufactura industrial de San Francisco del Rincón, Guanajuato, ha resultado también en otros cambios como los de la actividad comercial, que anteriormente era exclusivamente masculina. Ahora son las mujeres las que se dedican al comercio entre pueblos y ciudades de la región. La crisis de los últimos años dice Arias - ha hecho crecer esta vía de trabajo y de sobrevivencia femeninas en el campo y en este proceso ellas también han cambiado, "las bases mismas del poder patriarcal han sido minadas casi por todos lados" (ibid.243).

Sin embargo, en las regiones del sureste de México y en particular en Los Altos en donde no hay industria, las mujeres han estado involucradas de manera muy importante tanto en los mercados de productos agropecuarios como en el sector de servicios. Considero que sus formas actuales de participación económica son una combinación de las formas históricas dela experiencia laboral de las mujeres con las dinámicas particulares de los mercados capitalistas en esta región. Ellas no sólo se han ido acomodando a los empleos para sustituir a los hombres, respondiendo sólo influencias externas y ajenas, sino han sido ellas mismas las que han decidido adoptar y modificar una u otra forma de involucrarse a los mercados según sus conocimientos, experiencia de vida y habilidades ante las opciones de su entorno social.

Estos cambios han tenido consecuencias distintas para las comerciantes. Por ejemplo, en el caso de Los Altos de Chiapas, esta persistencia y renovación de la artesanía textil ha generado una amplia movilidad territorial de las mujeres rurales no así de las comerciantes urbanas coletas, a quienes su actividad las ha mantenido casi todo el tiempo al frente de sus locales comerciales que, en varios casos, son una extensión de su espacio doméstico. Sin embargo, ellas también han expresado su "realización como personas" al dedicarse a este trabajo, así relata una comerciante coleta:

\footnotetext{
...me casé y comenzamos a vivir. Me he realizado como esposa, bendito sea Dios, y me siento muy contenta porque tuve tres bijos con partos naturales. Entonces, vivía ya yo dependiente de su sueldo, pero en realidad como no había sido criada para eso, yo necesitaba realizarme como persona.....quería poner en práctica lo que mis papás me enseñaron: el negocio de las artesanía (Rus, ibid:: 84).
}

En el caso de las tseltales rurales, se ha dado una asociación entre el trabajo de textiles y la movilidad territorial que no se encuentra solamente entre las generaciones jóvenes, sino incluso las mujeres mayores relacionan el trabajo de textiles con una mayor independencia de las mujeres para movilizarse físicamente al asociar este trabajo con la utilización del transporte público moderno: dice doña Natividad López, anciana de Aguacatenango: 
Antes, cuando vendíamos sombrero, vamos a pie por eso necesitas de los hombres quienes te van a acompañar, ahora cuando las mujeres se van ya no llevan compañia, se van en carro. Con el trabajo de las blusas, si quieren ir a venderfuera las mujeres se van sin los hombres".

Considero que no se trata sólo de un modelo doméstico de relaciones laborales, lo doméstico se quedó atrás en este trabajo a domicilio pues para la gran mayoría de la mujeres no representa un confinamiento permanente en sus viviendas. Por supuesto que existen diferencias entre ellas según el lugar que hayan logrado ocupar en la producción. Aunque existe una movilidad territorial de la gran mayoría, no todas tienen oportunidad de salir hacia lugares tan lejanos como las líderes y representantes de organizaciones que han salido a lugares de Europa, Canadá y Estados Unidos. Sin embargo, la movilidad espacial aún en otra escala, como la de las mujeres más pobres que se dedican a trabajar a destajo y que por tanto, tienen que estar frecuentemente trasladándose de un lugar a otro para diferentes etapas del proceso de producción, permite que ellas amplíen su espacio de convivencia social, de relaciones de trabajo y de uso de tiempo libre, pues generalmente aprovechan sus salidas para asistir a diferentes eventos y visitas a familiares y amistades.

La percepción de lo doméstico puede ser distinta entre las mujeres según su experiencia de vida y de trabajo por tanto no es sólo el trabajo remunerado el que se amolda al trabajo doméstico sino éste también se amolda al primero. La opinión de las mujeres empleadoras tseltales al instalarse una máquina tortilladora en su pueblo fue: "Estoy muy contenta porque ya bay una tortillería en Aguacatenango, asi tengo más tiempo para mi trabajo porque la casa quita mucho tiempo".

Para terminar sólo comentaré que siguiendo la ruta de las artesanías he logrado conocer situaciones, cambios y respuestas en la vida y situación de las artesanas que confirman que para avanzar en el estudio de la condición social de las mujeres es necesario, por una parte, reconocer que su situación en la sociedad actual de México es inequitativa, pero también es indispensable conocer la diversidad de experiencias en contextos específicos en donde se pueden descubrir caminos que evitan el abandono pasivo y posibilitan el ejercicio de "la voluntad de ser" (Tarrés, 1996). ${ }^{16}$

Considero de acuerdo con Amorós (2001), que el feminismo es un test de la democracia, un test de todo movimiento emancipatorio pero también en desacuerdo con la misma autora, sostengo que no es posible definir a la condición femenina en relación con el espacio privado y verlo como un espacio de idénticas.

Me parece importante comentar como conclusión de las anteriores discusiones en relación con el género y trabajo artesanal que los cambios identitarios entre mujeres y hombres pueden darse de manera más rápida en ciertos contextos de culturas campesinas indígenas. No sólo son los factores exógenos y macrosociales los impulsores de cambios. Sugiero también que en nuestras sociedades coexisten diversas identidades y sistemas de género en los cuales el patriarcado no funciona como el eje orientador de las relaciones entre hombres y mujeres ni la subordinación es una característica que homogeneiza a las mujeres.

\section{Conclusiones}

La artesanía mexicana del siglo XXI es ahora, como siempre, un objeto elaborado manualmente que nos dice mucho de sus hacedoras: las artesanas y artesanos de las distintas regiones del país, pero si antes eran portadoras de la diversidad y riqueza cultural de cada grupo étnico, ahora también son reflejo de la interculturalidad y de su dinámica laboral y territorial. Las artesanas en el siglo XXI viajan por el país, por el continente, por el mundo, establecen relaciones con gente de otros países que los visitan, interactúan desde su entorno local con diversas culturas y reproducen parte de estas 
experiencias en sus objetos artesanales. Las innovaciones de la artesanía no sólo son reflejo del sentido utilitarista de los artesanos sino también expresan su moderna " tradicionalidad" que en la mayoría de los casos forma parte también de la modernidad de la pobreza.

He revisado la diversidad de rutas y caminos que han seguido las familias artesanas en regiones del país y como en estos procesos se han generado nuevas desigualdades sociales, nuevas formas de cooperación y nuevos conflictos que cuestionan la cohesión cultural contemplada muchas veces en la producción y el consumo de los objetos artesanales. Se puede concluir también que las nuevas significaciones en el consumo de la artesanía trascienden los ámbitos de lo estético, identitario y utilitario para pasar al ámbito de lo político.

En cuanto al vínculo entre género y artesanías, se ha señalado cómo en el contexto del desarrollo de capital y las transformaciones agrarias en México, las mujeres han tenido sus propias propuestas a través de las cuales han reconfigurado la identidad femenina. En varios estudios sobre género y procesos laborales de artesanía se muestra la existencia de espacios de acción que las mujeres han ocupado por decisión propia y que nos dicen que probablemente la identidad femenina está moldeada, construida por algo más que las experiencias de procesos sociales de exclusión, supuestamente relacionada con su sexo y cuyo papel en la sociedad es la reproducción biológica y la reproducción de la fuerza de trabajo. En particular, en la región de los Altos de Chiapas, las artesanías persisten a través de dos vías que las mujeres han construido y que han ampliado sus espacios de participación social en tiempos más cortos que en otras regiones.

Esta situación indica la necesidad de estudiar las relaciones sociales, identidades y nuevas situaciones laborales y de consumo no sólo como procesos de hegemonía y resistencia sino también como procesos de negociación constante en las continuas y múltiples interacciones entre etnias, identidades y nuevas culturas del mundo de la globalización, (García C. 1995).

\section{Notas}

${ }^{1}$ La cifra la proporciona el antropólogo argentino Carlos Mordó en entrevista de Arturo Cruz B. La Jornada, de enmedio 12 de noviembre de 2003, México, p.9a

2 Jiménez A.; entrevista a J. Iturriaga, director general de Culturas Populares del Consejo Nacional para la Cultura y las Artes. La Jornada, 11 de diciembre de 2000, México, p.44.

${ }^{3}$ Ejea en su estudio sobre el consumo de artesanías realizado en la Ciudad de México muestra cómo 49\% de los encuestados manifestó su gusto y compra de estos bienes por ser productos de una expresión colectiva, "gran parte de la población entrevistada las concibe como expresión propia del país,...usando frases como 'nuestras raíces', 'nuestra cultura', 'nuestra identidad nacional', 'por identificación para tener algo en mi casa que represente a México’...” (Ejea, T. 1998:374).

${ }^{4}$ Cuando hablo de globalización me refiero al conjunto de procesos resultado de las interrelaciones entre los actores sociales a través de todo el mundo. Procesos que implican no sólo la transnacionalización de la economía y la fragmentación de la producción sino también una nueva dinámica cultural. Los nuevos flujos mundiales han sido caracterizados por Appadurai A. (1996) como ethnoscapes (flujos de población: trabajadores, turistas, inmigrantes, exiliados); mediascapes (información e imágenes distribuidos en todo el mundo); technoscapes flujos producidos por tecnologías); finanscapes (intercambios monetarios en mercados mundiales); e ideoscapes (cadena de ideastérminos e imágenes que incluyen bienestar, soberanía, representación y democracia), (Mato, 2001; Appadurai, 1996; García C., 1999).

${ }^{5}$ Información verbal de Marcelina Aguilar, artesana, Oaxaca, Oax. Dic. 2003. Baltazar Acevedo, artesano: “ “...estos indígenas mixtecos apenas subsisten del tejido de sombreros de palma que venden a los coyotes a un precio de 10 pesos la pieza, que luego es vendida hasta 60. Cada sombrero les toma un tiempo de ocho a diez horas para concluirlo...” y se registra: “...” ( $L a$ Jornada, 17 y 18 de junio de 1999).

${ }^{6}$ Según Novelo (1976) los cuatro objetivos de la acción estatal en la promoción de las artesanías han sido: 1) su explotación comercial relacionada con el crecimiento del turismo extranjero 
e incrementar la reserva de divisas; 2) el fomento de su exportación como apoyo al equilibrio de la balanza comercial; 3) la creación de empleos y fuentes complementarias de ingresos para las familias del sector rural; 4) la creación de un sistema simbólico representativo de la capacidad creativa nacional que sirva a la integración de la cultura nacional.

${ }^{7}$ Sistema de poder del hombre sobre las mujeres y generaciones menores. El hombre ejerce el poder a través del control sobre la sexualidad, los recursos materiales, el trabajo y la participación en los procesos de toma de decisiones y en las instituciones de gobierno.

${ }^{8}$ Mato se refiere a representanciones sociales como "formulaciones sintéticas de sentido, descriptibles y diferenciables, producidas por actores sociales como formas de interpretación y simbolización de aspectos clave de su experiencia social", (2001:17).

${ }^{9}$ Mercedes Olivera (1994) señala cómo las mujeres indígenas pasaron de "de la participación comunitaria en actividades meramente rituales, como esposas de los mayordomos o acompañantes en las fiestas de los santos patronos, las mujeres indígenas fueron participando en los colectivos de reflexión y análisis de su realidad, en los colectivos de abasto, de comercialización, producción artesanal o agropecuaria. Participaron de los servicios de alfabetización, educación primaria y salud comunitaria y no estuvieron exentas de la participación corporativizada a manos del partido oficial a partir de la década de los 70" (p.66).

${ }^{10} \mathrm{El}$ poblado de Aguacatenango colinda con el municipio de Amatenango, tiene un número aproximado de 3,000 habitantes tseltales. Las principales actividades son la producción agropecuaria y la producción textil. El pueblo de Amatenango del Valle se ubica en la zona de los Altos de Chiapas, en el centro del estado, a unos treinta kilómetros de la ciudad de San Cristóbal de Las Casas. El patrón de asentamiento es del tipo de las comunidades tseltales: un pueblo principal y un cierto número de caseríos llamados "barrios". Tiene aproximadamente 6,000 habitantes tzeltales que se dedican al cultivo de maíz-frijol y a la alfarería. Parte de la población femenina de sus barrios se dedica también a la maquila de textiles.

${ }^{11}$ La población de las localidades del valle TeopiscaAmatenango son grupos mestizos y tseltales. Aunque varios pueblos del área como Aguacatenango y El Puerto pertenecen administrativamente a la región de Valles Centrales, culturalmente forman parte de la población tseltal del sur de Los Altos de Chiapas: "una regionalización más precisa obligaría a abandonar al municipio como unidad territorial mínima e incluir dentro de la región de los Altos tanto la porción occidental del municipio de Ocosingo como el pueblo de Aguacatenango, que forma parte del municipio de Venustiano Carranza”, (Viqueira, 1995:35).

${ }^{12}$ Sulca menciona que existen diferentes versiones sobre la nominación de "coletos" a los habitantes de San Cristobal, unas dan enfásis al aspecto histórico, otras a los aspectos geográficos, al comportamiento de los habitantes y la vestimenta, "Según la interpretación que hace Francis, (1992: 124) coleto es un gentilicio que probablemente venga del latín Corpus-Oris, cuerpo-traje con faldones, ya que los sancristobalenses usaban levita. O bien de "recoleto", pues vivían en retiro y abstracción, o de "coleta" porque usaban coleta a la usanza de la época...” (Sulca, 1996:67)

${ }^{13}$ Esta iglesia se ubica en el centro histórico de San Cristóbal y tiene una parte de su fachada en algamaza (esquema de tradición mudéjar) En estos relieves de flores se expresa un simbolismo idea del universo prehispánico.

${ }^{14}$ Sobre el comercio, se ha señalado que es una de las actividades favoritas de las mujeres por la flexibilidad y los tiempos de venta que se adaptan a las necesidades de las labores del hogar. En el presente caso, la mayoría de los principales establecimientos comerciales de las coletas, son parte de la vivienda.

${ }^{15}$ Desde el punto de vista cultural, a la pluridimensionalidad de la identidad señalada por Giménez (1993:26) hay que agregar esta identidad laboral múltiple, cuya importancia es indudable en la conformación de las identidades femenina y masculina. La identidad de los grupos rurales también se va reconstruyendo no sólo por las relaciones laborales y su posición en el oficio artesanal sino también por la interacción constante con otros grupos sociales a través de esta reconversión de sus productos.

${ }^{16}$ La "voluntad de ser" es una metáfora que la poeta Gabriela Mistral creó para definir a las mujeres. Su convivencia con las nahuas, totonacas y ladinas de la región de la sierra de Puebla, la llevó a afirmar que las "mujeres de América Latina son una voluntad de ser”, (Tarrés:1992). Dice Tarrés que en esta metáfora se destaca al mismo tiempo el valor de la libertad en la definición de la identidad de la mujer y su fragilidad como sujeto. 


\section{Bibliografía}

Aguiar, Mirna, 1998, "El trabajo de la mujer rural en las maquiladoras de Yucatán”, en, Mummert, Gail, Ramirez Luis Alfonso (editores) Rehaciendo las diferencias, El colmich, México, pp. 159-178.

Appadurai, Arjun, 1996, Modernity and large. Cultural dimensions of Globalization, Minneapolis-London, University of Minnesota Press, EUA.

Arizpe, Lourdes, 1973, Parentesco y economía en una sociedad nabua, INI, México.

Alberti, Pilar, 1994, La identidad de género en tres generaciones de mujeres indigenas. Tesis para optar por el grado de Maestra en Antropología Social, ENAH, México.

Alberti, P. 1997. "La identidad de género y étnica como base de las estrategias de adaptación de las mujeres indígenas a la crisis". En Alberti P. y E. Zapata, Estrategias de sobrevivencia de las mujeres campesinas e indígenas ante la crisis. Colegio de Posgraduados. Programa de Estudios del Desarrollo Rural, Área de Género, México, pp.169-187

Arias, P. 1992. Nueva rusticidad mexicana, conaculta, México. Amorós, Celia, 1994. Feminismo. Igualdady diferencia. Colección Libros del Programa Universitario de Género, unAm, México. Benería Lourdes y Marta Roldán, 1992, Las encrucijadas de clase y género. Trabajo a domicilio, subcontratación y dinámica de la unidad doméstica en la ciudad de México, FCE, México.

Bonnarcorsi, Nélida, 1990. El trabajo obligatorio indígena en Chiapas, Siglo XVI, unAm, México.

Bourdieu, Pierre. y L. Wacquant, 1995, Respuestas. Por una antropología reflexiva, Grijalbo, México.

Castilleja, Aída,. 1998. "Jarácuaro, pueblo productor de sombreros" En Mummert, Gail, Ramirez L.A. (editores) Rehaciendo las diferencias, El colmich, México, pp. 37-71.

Castro, Yolanda, 2003. "J'pas Joloviletik-Jolom MayaetikKinal Antzetik: an organizational experience of indigenous and mestiza women". En Women of Chiapas. Making history in times of struggle and hope, Eber Chistine and Kovik, (editores), Routledge, New York and London.

Clements, Helen, 1988, "Mujeres, trabajo y cambio social: el caso de dos comunidades oaxaqueñas" en Las mujeres en el campo. Memoria de la Primera Reunión nacional sobre mujeres campesinas en México, Universidad Autónoma Benito Juárez de Oaxaca, México, pp. 245-257.
Chiñas, Beatriz, 1975, Mujeres de San Juan. La mujer zapoteca del Istmo en la economía, SEPSETENTAS, México.

Ejea, María Teresa, 1998, "El sutil encanto de las artesanías. Usos en la ciudad” en García Canclini Néstor (coord.) Cultura y comunicación en la ciudad de México, Modernidad y multiculturalidad: la cindad de México a fin de siglo, UAM, México, pp. 369-387.

Fábregas, Andrés, 1993, "El textil como resistencia cultural" en Artes de México Núm. 19, Primavera 1993, México, pp. 25-27.

García Raúl y Luis García, 1991, Lagunas, deterioro ambientaly tecnológico en el campo semiproletarizado. El Colegio de México, México.

García Canclini, Néstor, 1982, Las culturas populares en el capitalismo, Nueva Imagen, México.

—, 1989, Culturas Hibridas. Estrategias para entrary salir de la modernidad, Grijalbo, México.

—, 1995, Consumidores y Ciudadanos, Grijalbo, México.

—, 1999, La Globalización Imaginada, Paidós, México.

Giménez, G., 2000, "Materiales para una teoría de las identidades sociales" en Valenzuela Arce José M. (coord.) Decadencia y auge de las identidades. Cultura nacional, identidad culturaly modernización, El Colegio de la Frontera Norte, Plaza y Valdés, México, pp. 45-78.

Good-Eshelman, Catharine, 1988, Haciendo la lucha. Arte y comercio nahuas de Guerrero, FCE, México.

González Soledad y Vania Salles, (coords.) 1995, “Mujeres que se quedan, mujeres que se van... continuidad y cambios de las relaciones sociales en contextos de aceleradas mudanzas rurales", en Relaciones de género y transformaciones agrarias: estudios del campo mexicano, PIEM. El Colegio de México, México, pp.15-50.

Hernández Francisco Javier y Elena de la Cruz Narváez, 1992, "Las sociedades de autogestión en los Altos de Chiapas", tesis para obtener el título de Licenciados en Sociología, UNACH, Campus III, Chiapas.

Lara, Sara, 1995, "Las empacadoras de hortalizas en Sinaloa: historia de una calificación escatimada” en González, Soledad y Vania Salles, (coords.) Relaciones de género y transformaciones agrarias: estudios sobre el campo mexicano, El Colegio de México, México, Pp. 165-185.

Lazos, Elena, 1995, "De la candela al mercado: el papel de la mujer en la agricultura comercial del sur de Yucatán" En 
González, Soledad y Vania Salles, (coords.), Relaciones de género y transformaciones agrarias: estudios sobre el campo mexicano, El Colegio de México, pp. 91-133

Littlefield, Alice, 1976, La industria de las hamacas en Yucatán, México., INI-SEP, México.

Martínez Porfirio, 1988, Arte popular y artesanias artísticas en México. Un acercamiento. Lecturas Mexicanas 108, sep, México. Mato, Daniel, 2001, "Globalización (que no es lo mismo que "Libre Comercio"), Cultura (que es más que "Bellas Artes", Culturas Populares, e Industrias Culturales") y Transformaciones Sociales", Ponencia presentada en la $1^{\mathrm{a}}$. Conferencia Regional de la Asociación Internacional de Sociología en América Latina y el Caribe, Isla de Margarita, Mayo del 2001.

—, 2001, "Des-fetichizar la "globalización": basta de reduccionismos, apologías y demonizaciones, mostrar la complejidad y las prácticas de los actores", en Mato, Daniel, (comp.) Estudios Culturales sobre cultura y transformaciones sociales en tiempos de globalización 2, CLACSO, Argentina, pp.147-177.

Maurer, E. s/f. "Los tseltales. ¿Paganos o cristianos? Su religión ¿sincretismo o síntesis?”, México.

Moctezuma, Patricia, 1998, "Las artesanas endeudadas de Patamban" en Mummert, Gail, Luis Alfonso Ramírez, (edits.), Rehaciendo las diferencias, El colmich, México, pp. 73-101.

Mora, Isabel, 1998, “Las aguacateras de Caltzontzin: mujeres indígenas en circuitos comerciales extralocales" en Mummert, Gail, Luis Alfonso Ramírez, (edits.), Rehaciendo las diferencias, El COLMICH, México, pp. 103-130.

Morris Walter, 1977, Mil años de tejido en Chiapas, Instituto de la Artesanía Chiapaneca, México.

Mummert, Gail, Peréz Prado Luz, 1998, "Introducción: la construcción de identidades de género vista a través del prisma del trabajo femenino" en Mummert, Gail, Luis Alfonso Ramírez, (edits.) Rehaciendo las diferencias, El Colegio de Michoacán, México, pp. 15-32.

Murillo, Gerardo, 1980, Las artes populares en México, INI, México.

Nash, June, 1994, "La producción artesanal y el desarrollo de la industria: cambios en la transmisión cultural por medio de las mercancías" en Mario Ruz, (ed), Semillas de la Industria. Transformaciones de la tecnología indígena en las Américas. CIESAS, México, pp. 99-115.
Novelo, Victoria, 1976, Artesanías y capitalismo en México, SEP-INHA, México.

—, 1993, Las Artesanías en México, Instituto Chiapaneco de Cultura, México.

Ramos, Teresa, 2000, "Género e identidades femeninas: mujeres de los Altos de Chiapas", Anuario 2000 del CESMECAUNICACH, México, pp. 259-287.

—, 1992, Economía de las unidades campesinas y producción de sombreros en la Mixteca Alta de Oaxaca. Estudio de caso en la comunidad Magdalena Peñasco, Distrito de Tlaxiaco, Tesis de licenciatura en economía, Facultad de Economía de la unAm, México.

Rejón Lourdes, 1998, "Mujer maya, mujer bordadora. Las cooperativas de artesanas en el oriente yucateco", en Mummert, Gail, Luis Alfonso Ramírez, (editores) Rehaciendo las diferencias, El colmich, México, pp. 269-291.

Rosado, Georgina, 1998, "Construcción del género, identidad política y procesos de trabajo en las empacadoras pesqueras del litoral yucateco" en Mummert, Gail, Luis Alfonso Ramírez, (editores) Rehaciendo las diferencias, El cOLmich, México, pp.133-155.

Rus, Diane, 1990, "La crisis económica y la mujer indígena: el caso de Chamula, Chiapas" Serie Documentos de Trabajo sobre el cambio en el campo chiapaneco, INAMERAC, México. —, 1997, Mujeres de tierra fría. Conversaciones con las coletas, UNICACH, México.

Stephen, Lyn, 1991, Zapotec Women, University of Texas Press, Austin texas.

—, 1990. "La cultura como recurso" en América Indígena Núm. 4. México, pp. 117-157.

Sulca, Edgar, 1996. Nosotros los coletos. Identidad y cambio en San Cristóbal de Las Casas. CESMECA-UnICAH, Separata, Anuario 1996, México.

Tarrés, Maria Luisa, 1992, “Introducción. La voluntad de ser" en Tarrés, M.L. (comp.) La voluntad de ser. Mujeres de los noventas. El Colegio de México, pp. 21-46.

Viqueira, Juan Pedro, 1995, “Chiapas y sus regiones” en Viqueira, Juan Pedro y Mario H. Ruz, (editores) Chiapas: los rumbos de otra historia, UNAM-CIESAS-CEMCA-UAG, México, pp.19-40.

O’Brian, R., 1992, “Un mercado indígena de artesanías en los Altos de Chiapas: persistencia y cambio en las vidas de las vendedoras mayas" en Mesoamérica 23 Junio, Guatemala, pp. $79-84$. 
Olivera, Mercedes, 1994, “Aguascalientes y el movimiento social de las mujeres chiapanecas. En: Soriano, Silvia, (coord.) A propósito de la insurgencia en Chiapas, Asociación para el Desarrollo de la Investigación Científica y Humanística en Chiapas, San Cristóbal de Las Casas, México, pp. 57-80.

Turok, Marta, 1988, Cómo acercarse a la artesanía, SEP -Plaza Valdés, México.
Vargas, Gabriela, s/f. "Globalización y artesanías. Organizaciones artesanales en Chiapas", Documento impreso.

Villafuerte, Daniel, 2001, "Chiapas: los espacios opacos de la globalización”, en Pueblos y fronteras núm. 1, PROIMMSE-UNAM, México, pp. 147-167. 